\title{
Experimental and Theoretical Evaluation on Thermoelectricity for SPS-Joined p-n Module in Bi-Te System
}

\author{
Sang Seok Kim ${ }^{1, *}$, Shigeo Yamamoto ${ }^{2}$, Tatsuhiko Aizawa ${ }^{2}$ and Atsushi Yamamoto ${ }^{3}$ \\ ${ }^{1}$ Research Center for Advanced Science and Technology, University of Tokyo, Tokyo 153-8904, Japan \\ ${ }^{2}$ Center for Collaborative Research, University of Tokyo, Tokyo 153-8904, Japan \\ ${ }^{3}$ Energy Electronics Institute, National Institute of Advanced Industrial Science and Technology, Tsukuba 305-8568, Japan
}

\begin{abstract}
Thermoelectric p-n modules are prepared by the spark plasma sintering (SPS) solid bonding for experimental and theoretical evaluation on their thermoelectricity. Both p-type $\left(\mathrm{Bi}_{0.4} \mathrm{Sb}_{1.6} \mathrm{Te}_{3}\right)$ and n-type $\left(\mathrm{Bi}_{2} \mathrm{Te}_{2.85} \mathrm{Se}_{0.15}\right)$ materials are prealloyed from elemental granule mixture via the bulk mechanical alloying, shear-extruded to control their anisotropic texture and joined to fabricate p-n modules. The mutual atomic diffusion layer across the p-n interface is controlled down to $2 \mu \mathrm{m}, 0.04$ times narrower than that for hot-pressed p-n interface. Open-circuit voltage and resistance of p-n modules are measured for various interface layer height. They are compared with theoretical estimates via the computer-aided analysis. Analytical expressions are proposed to estimate the thermoelectric characteristics on p-n module. The power generation characteristics of $\mathrm{p}$-n modules is also evaluated for various temperature differences between cold and hot sources.
\end{abstract}

(Received October 18, 2004; Accepted April 4, 2005; Published July 15, 2005)

Keywords: bismuth telluride, p-n junction, thermoelectricity, power generation, spark plasma sintering, computer-aided analysis

\section{Introduction}

A thermoelectric generator is an attractive thermal engine in which charge carriers serve as a working fluid. ${ }^{1)}$ Without moving parts, it is silent in operation and very reliable. Recently, this concept is accepted as a candidate unit of fast breeder nuclear reactor. Liquid lithium is used as a coolant and its thermally loading energy is converted to electricity via the thermoelectric generators. ${ }^{2)}$ A conventional thermoelectric generator usually consists of a series of p- and n-type bulk thermoelectric materials. In the conventional module design, they are sandwiched by ceramic plates, which have electrical insulation and thermal conductivity. The soldering process is used for joining their $\mathrm{p}$-n modules with copper electrode. Interface between solders and $p-n$ module is subjected to thermal cyclic loading when the thermoelectric device is set up to generate the electricity from the prescribed temperature difference between heat sources and sinks. Cracks are often detected at the vicinity of interface because of thermal cyclic fatigue. Many trials were reported in literature to fabricate the crack-free $\mathrm{p}$-n modules. Among them, Nishida ${ }^{3)}$ employed the directly pressing and sintering method to fabricate a U-type $\mathrm{FeSi}_{2}$ base $\mathrm{p}$-n module without soldering.

In the present study, the spark plasma sintering method is employed to eliminate a demerit of hot pressing for fabrication of $p-n$ module. Large electric resistance at the joined interface by hot pressing is significantly reduced to minimize the loss of output power in the module. Both p-type and n-type $\mathrm{Bi}-\mathrm{Te}$ materials, or, $\mathrm{Bi}_{0.4} \mathrm{Sb}_{1.6} \mathrm{Te}_{3}$ and $\mathrm{Bi}_{2} \mathrm{Te}_{2.85} \mathrm{Se}_{0.15}$, are prepared by the bulk mechanical alloying (BMA). Anisotropic texture in these materials is precisely controlled by the shear extrusion processing. ${ }^{4,5)}$ The fabricated fully dense $\mathrm{p}$ - and $\mathrm{n}$-thermoelectric semiconductors are joined in solid by the spark plasma sintering (SPS).

Both the Seebeck coefficient $\left(\alpha_{\mathrm{p}-\mathrm{n}}\right)$ and the resistance $\left(R_{\mathrm{p}-\mathrm{n}}\right)$ of a whole $\mathrm{p}-\mathrm{n}$ module are measured for various interface layer heights $\left(h_{\mathrm{i}}\right)$ and temperature differences $(\Delta T)$. The thermal analysis as well as the electric current density analysis is made to theoretically evaluate the experimentally measured thermoelectric module properties. Analytical expressions for $\mathrm{p}-\mathrm{n}$ module electricity are proposed to optimize the thermoelectric effect on $\mathrm{p}-\mathrm{n}$ module.

\section{Experimental and Simulation Procedure}

Both $\mathrm{p}$ and $\mathrm{n}$ type materials were prealloyed from the elemental granule mixture via the bulk mechanically (BMA) and shear-extruded to have preferable texture with anisotropy. The details of experimental conditions were listed in Table 1. The shear-extruded dense billets were cut to a sample with the size of $12 \times 8 \times 2 \mathrm{~mm}^{3}$ as shown in Fig. 1 . These samples were polished and joined in solid by SPS (Spark Plasma Sintering) at $523 \mathrm{~K}$ by $10.4 \mathrm{MPa}$ for $0.3 \mathrm{ks}$ in

Table 1 Details of experimental conditions of BMA and shear extrusion.

\begin{tabular}{|c|c|c|c|c|c|c|}
\hline \multirow{2}{*}{\multicolumn{2}{|c|}{ Alloying materials }} & \multicolumn{2}{|c|}{ BMA } & \multicolumn{3}{|c|}{ Shear extrusion } \\
\hline & & $\begin{array}{c}\begin{array}{c}\text { Number of } \\
\text { cycles }\end{array} \\
800\end{array}$ & $\begin{array}{c}\text { Atmosphere } \\
\text { In Argon }\end{array}$ & $\begin{array}{c}\text { Temperature }(\mathrm{K}) \\
753\end{array}$ & $\begin{array}{l}\text { Atmosphere } \\
\text { Ar, } 1 \text { atm }\end{array}$ & $\begin{array}{c}\begin{array}{c}\text { Crosshead speed } \\
(\mathrm{mm} / \mathrm{min})\end{array} \\
0.5\end{array}$ \\
\hline n-type & $\mathrm{Bi}_{2} \mathrm{Te}_{2.85} \mathrm{Se}_{0.15}$ & 800 & In Argon & 683 & Ar, $1 \mathrm{~atm}$ & 0.5 \\
\hline
\end{tabular}

*Graduate Student, The University of Tokyo 


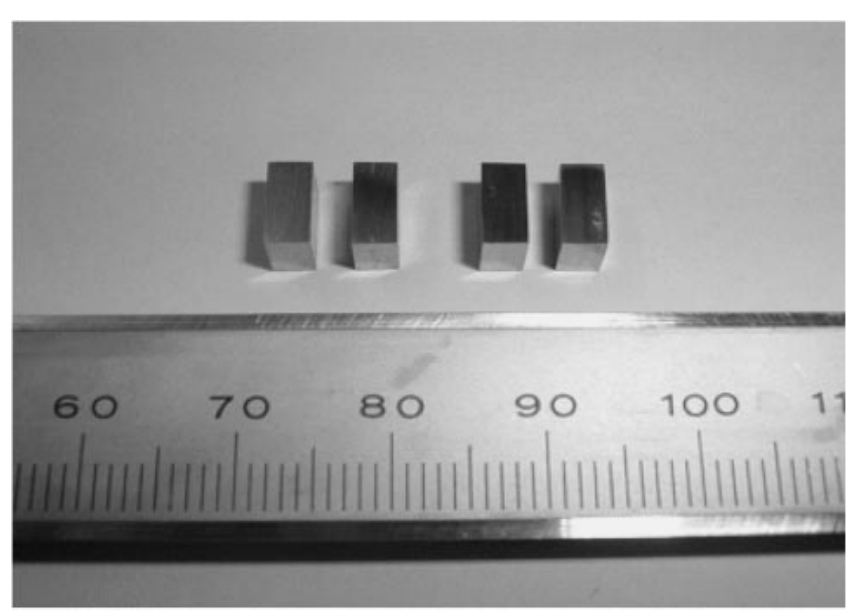

Fig. 1 Fully dense p-type and n-type thermoelectric billets.
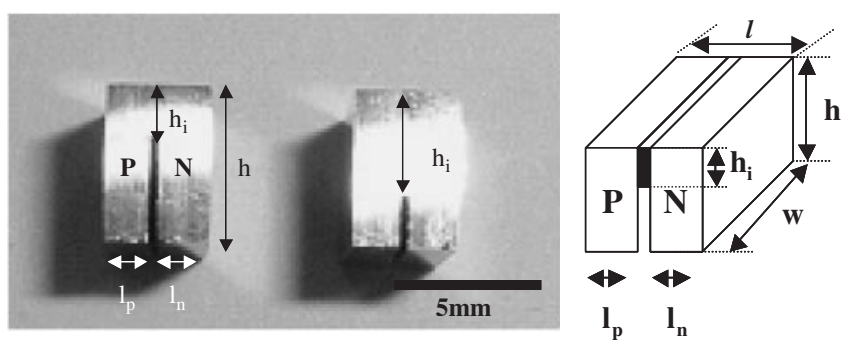

Fig. 2 Two types of $\mathrm{p}-\mathrm{n}$ module samples with different interface height $\left(h_{\mathrm{i}}\right)$.

vacuum. As-SPS joined pn module with its illustration is shown in Fig. 2. To fabricate the sample with a metallic insert, the nickel coated copper film is sandwiched by p- and n-type materials and subjected to SPS in the same condition. These as-SPS joined pn billets were further machined to have a wedge along the $\mathrm{p}-\mathrm{n}$ interface with different interface layer $\left(h_{\mathrm{i}}\right)$. The output voltage and the output power were measured as the load characteristic data. The scanning electron microscopy (SEM) and energy dispersion spectrometry (EDS) were employed to analyze the variation of both $\mathrm{Bi}$ and $\mathrm{Sb}$ concentration across the $p-n$ interface. The bar-shape, $p-n$ billet sample with the constant cross-section area of $\mathrm{S}=6.2 \mathrm{~mm}^{2}$ was also fabricated by SPS for measurement of the resistance versus displacement curve. Applying a constant current between both ends of this sample, the voltage between the probe and one end of sample was measured by moving the location of probe across $p-n$ interface. Electric resistivity across the p-n interface was calculated from this resistance versus distance curve.

Theoretical study by finite element analysis was employed to estimate the electric current density and temperature distributions in each module. Computational conditions of finite element analysis are listed in Table 2, including the boundary conditions, the loading conditions and the material properties. Commercial finite element code, ANSYS was used for two-dimensional analysis. Quadrilateral element (type of PLANE67) with four nodes and two degrees of freedom for each node was employed for discretization in finite element analysis. Then, both temperature and current
Table 2 Computational conditions for analysis of the electric current density and temperature distributions in two types of samples, M-I and M-II.

\begin{tabular}{|c|c|c|c|c|}
\hline \multicolumn{3}{|c|}{ Sample } & M-I & M-II \\
\hline \multicolumn{3}{|c|}{ Program system } & \multicolumn{2}{|c|}{ ANSYS6.1 } \\
\hline \multicolumn{3}{|c|}{ Type of element } & \multicolumn{2}{|c|}{$\begin{array}{l}\text { Four-node } \\
\text { quadrilateral element }\end{array}$} \\
\hline \multicolumn{3}{|c|}{ Number of elements } & 6528 & 6312 \\
\hline \multicolumn{3}{|c|}{ Number of nodes } & 6731 & 6551 \\
\hline \multicolumn{3}{|c|}{$\begin{array}{l}\text { Boundary } \\
\text { conditions }\end{array}$} & \multicolumn{2}{|c|}{$q_{\text {lateral }}=0$} \\
\hline \multirow{4}{*}{ Temperature } & \multirow{4}{*}{$\begin{array}{l}\text { Loading } \\
\text { conditions }\end{array}$} & $T_{\mathrm{h}}, / \mathrm{K}$ & 320 & 327 \\
\hline & & $T_{\mathrm{c}}, / \mathrm{K}$ & 290 & 290 \\
\hline & & $k_{\mathrm{p}}, / \mathrm{W} / \mathrm{mK}$ & 1.50 & 1.50 \\
\hline & & $k_{\mathrm{n}}, / \mathrm{W} / \mathrm{mK}$ & 1.50 & 1.50 \\
\hline \multirow{4}{*}{ Current density } & \multirow{4}{*}{$\begin{array}{l}\text { Loading } \\
\text { conditions }\end{array}$} & $\left(V_{\mathrm{oc}, \mathrm{p}}\right) / 2, / \mathrm{V}$ & $0.304 \times 10^{-2}$ & $0.375 \times 10^{-2}$ \\
\hline & & $\left(V_{\mathrm{oc}, \mathrm{n}}\right) / 2, / \mathrm{V}$ & $-0.186 \times 10^{-2}$ & $-0.230 \times 10^{-2}$ \\
\hline & & $\rho_{\mathrm{p}}, / \Omega \mathrm{m}$ & 0.985 & $\times 10^{-5}$ \\
\hline & & $\rho_{\mathrm{n}}, / \Omega \mathrm{m}$ & 0.410 & $\times 10^{-5}$ \\
\hline
\end{tabular}

density are interpolated by the bi-linear function in this element model. Typical mesh subdivision as well as boundary conditions is illustrated in Fig. 3. In the thermal analysis or in Fig. 3(a), $T=T_{\mathrm{h}}$ at the upper edge and $T=T_{\mathrm{c}}$ at the lower edge. Along the both sides, the heat flux is assumed to be zero or $q_{\text {lateral }}=0$. The thermal conductivity is considered to be constant for simplicity. From the calculated temperature distribution, the voltage distribution is estimated by assuming that the gradient of voltage is constant in each element. The open circuit voltage $\left(V_{\mathrm{oc}}\right)$ is calculated by integrating the voltage difference in a p-n module circuit. In the computation of current density distribution, the voltage at the end of terminals is given by $V_{\mathrm{oc}} / 2$ in order that the output power is maximized. At the upper edge, $V$ is assumed to be zero.

\section{Results and Discussions}

\subsection{Interface characteristics of p-n billet}

Variation of bismuth and antimony concentrations across the interface measured by EDS is shown in Fig. 4. Steep gradient in bismuth and antimony concentrations is seen at the narrow region. The interface layer thickness is approximately $2 \mu \mathrm{m}, 0.04$ times narrower than that for hot-pressed p-n interface. ${ }^{6}$ )

The measured electrical resistance versus distance curve across this interface is shown in Fig. 5. From this curve, the interface resistivity $\rho_{\mathrm{i}}$ is estimated together with internal resistivities, both in $\mathrm{p}$ - and n-type materials. This $\rho_{\mathrm{i}}$ is defined by

$$
\rho_{\mathrm{i}}=\Delta R_{\mathrm{i}} \frac{S}{t}
$$

where $\Delta R_{\mathrm{i}}$ is the resistance jump, and the thickness of transient zone in Fig. 5.

The processing conditions and characteristics of $\mathrm{p}-\mathrm{n}$ interface layer are compared in Table 3 between hot-pressed 
(a)

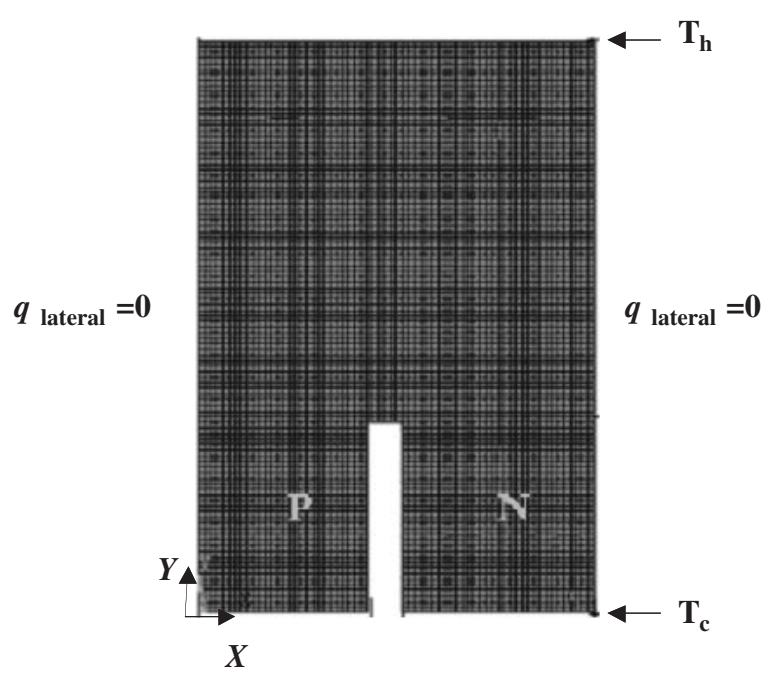

(b)

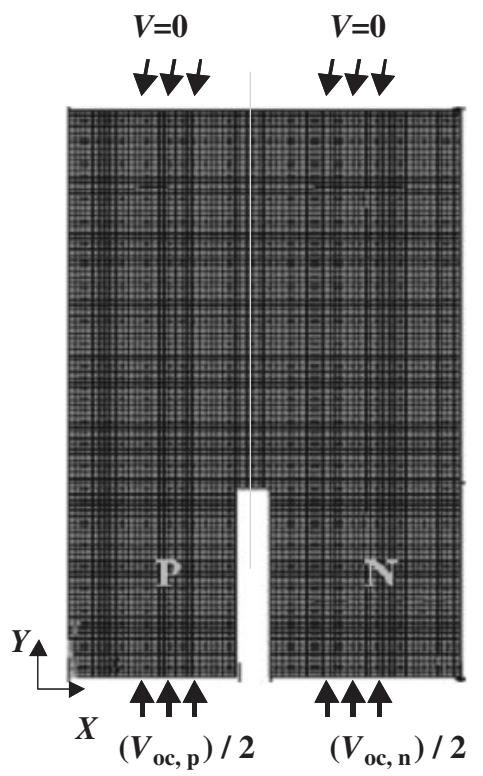

Fig. 3 Typical mesh subdivision and boundary conditions in the computeraided analysis for a p-n module sample: (a) Thermal analysis, and (b) Electric current density analysis.

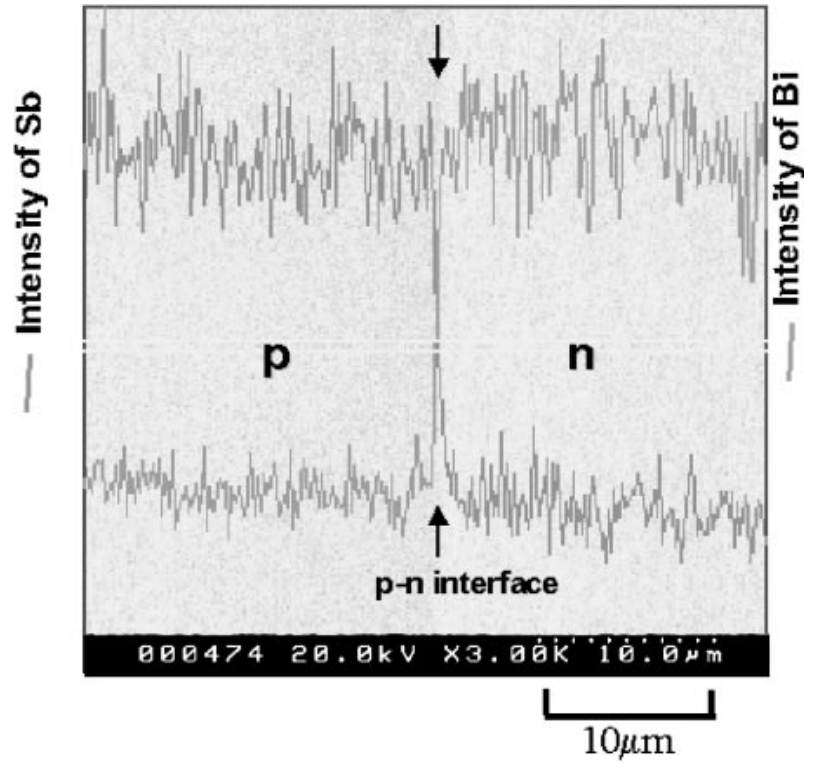

Fig. 4 Variation of bismuth and antimony concentrations across the p-n interface layer for the module sample without a metallic insert.

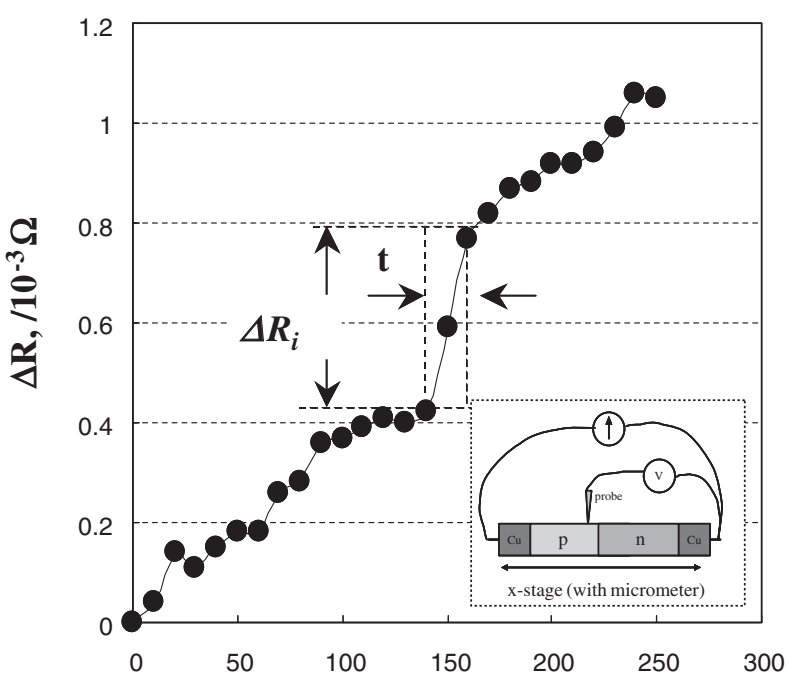

Displacement, $\mathbf{x} / \mu \mathrm{m}$

Fig. 5 Variation of electric resistance across the p-n interface layer.

Table 3 Comparison of processing conditions and characteristics at the $\mathrm{p}-\mathrm{n}$ interface layer between hot-pressed and SPS bonded p-n module.

\begin{tabular}{|c|c|c|c|c|c|c|c|}
\hline & \multirow[b]{2}{*}{ Module system } & \multicolumn{3}{|c|}{ Processing conditions } & \multirow{2}{*}{$\begin{array}{l}\text { Interface layer } \\
\text { thickness, } \\
(\mu \mathrm{m})\end{array}$} & \multirow{2}{*}{$\begin{array}{l}\text { Transient zone } \\
\text { thickness, } t \\
\qquad(\mu \mathrm{m})\end{array}$} & \multirow{2}{*}{$\begin{array}{c}\text { Interface } \\
\text { resistivity, } \rho \\
\left(\times 10^{-5} \Omega \mathrm{m}\right)\end{array}$} \\
\hline & & $\begin{array}{c}\text { Temperature } \\
(\mathrm{K})\end{array}$ & $\begin{array}{c}\text { Pressure } \\
(\mathrm{MPa})\end{array}$ & $\begin{array}{c}\text { Time } \\
(\mathrm{ks})\end{array}$ & & & \\
\hline $\begin{array}{l}\text { Present } \\
\text { method }\end{array}$ & $\begin{array}{l}\text { p-type: } \mathrm{Bi}_{0.4} \mathrm{Sb}_{1.6} \mathrm{Te}_{3} \\
\text { n-type: } \mathrm{Bi}_{2} \mathrm{Te}_{2.85} \mathrm{Se}_{0.15}\end{array}$ & 523 & 10.4 & 0.3 & 2 & 20 & 11.8 \\
\hline
\end{tabular}

and SPS bonded pn billets. SPS method has preferable features to fabrication of $\mathrm{p}-\mathrm{n}$ modules: lower operation temperature and shorter duration time than hot pressing. Furthermore, since a pulse electric current is applied to a series circuit of (p-type material) $\rightarrow$ (p-n interface $) \rightarrow(n-$ type material), the resistant $p-n$ interface is only joule-heated and successfully joined in shorter time and with low applied energy in total. 
Table 4 Electric resistivity and geomertric dimensions of module samples fabricated by SPS solid bonding with and without nickel coated copper film.

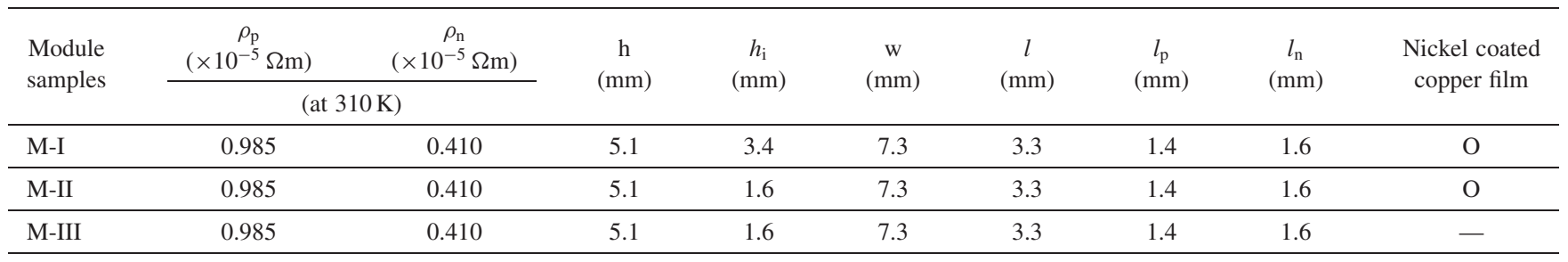

In SPS sample, $\rho_{\mathrm{i}}=11.8 \times 10^{-5} \Omega \mathrm{m}$ while $\rho_{\mathrm{i}}=12.5 \times$ $10^{-5} \Omega \mathrm{m}$ in hot-pressed sample. There is little significant difference in $\rho_{\mathrm{i}}$ between two samples even when the interface layer thickness of SPS sample is 25 times smaller. This fact implies that $\rho_{\mathrm{i}}$ does not depend on the thickness of interface layer. That is, the p-n interface layer in the order of $\mu \mathrm{m}$ has an intrinsic inner resistivity to carrier depletion state. This $\rho_{\mathrm{i}}$ might well decrease if the p-n interface thickness is reduced to nanometer range enough to be conductive via the tunneling effect. Otherwise the metallization is necessary to eliminate the carrier depletion zone at the p-n interface.

\subsection{Evaluation on the p-n module resistance}

Three types of module sample (M-I, II and III) were prepared as summarized in Table 4. Most of geometrical dimensions are nearly the same except for $h_{\mathrm{j}}$. To reduce the interface resistance, a copper film with the thickness of $50 \mu \mathrm{m}$ metallized at $363 \mathrm{~K}$ for $1.8 \mathrm{ks}$ by electroless nickel coating, was inserted between $\mathrm{p}$ - and n-type materials in both $\mathrm{M}-\mathrm{I}$ and M-II modules. M-III sample has the same geometric dimensions as M-II but it has no metallic insert. Identifying the p-n module as a series circuit, a total p-n resistance, $R_{\mathrm{p}-\mathrm{n}}$ is expressed by

$$
\begin{aligned}
R_{\mathrm{p}-\mathrm{n}} & =R_{\mathrm{p}-\operatorname{leg}}+R_{\mathrm{n}-\operatorname{leg}}+R_{\text {bonded-area }}+\Delta R_{\mathrm{i}}, \\
& =\rho_{\mathrm{p}} \frac{h-h_{\mathrm{i}}}{l_{\mathrm{p}} w}+\rho_{\mathrm{n}} \frac{h-h_{\mathrm{i}}}{l_{\mathrm{n}} w}+R_{\text {bonded-area }}+\rho_{\mathrm{i}} \frac{t}{h_{\mathrm{i}} w} .
\end{aligned}
$$

Here, $R_{\mathrm{p}-\operatorname{leg}}$ and $R_{\mathrm{n}-\operatorname{leg}}$ denote the resistance of $\left(h-h_{\mathrm{i}}\right) \times w$ area at p- and n-type materials, respectively, and $R_{\text {bonded-area }}$ is the resistance of $\mathrm{p}$-n bonded area with $h_{\mathrm{i}} \times w$. Variation of total $\mathrm{p}$-n resistance $\left(R_{\mathrm{p}-\mathrm{n}}\right)$ with temperature differences $\left(\Delta T_{(\mathrm{h}-\mathrm{c})}\right)$ between cold and hot sources is shown in Fig. 6. Increase of $R_{\mathrm{p}-\mathrm{n}}$ in all modules with $\Delta T_{(\mathrm{h}-\mathrm{c})}$ is mainly attributed to decrease of the carrier mobility by the carrierphonon scattering. Even having the same interface layer height $\left(h_{\mathrm{i}}\right), R_{\mathrm{p}-\mathrm{n}}$ of M-II is smaller than that of M-III. The carrier depletion zone is reduced by the metallization at the $\mathrm{p}$ $\mathrm{n}$ interface. For M-I with $h_{\mathrm{i}}=3.4, R_{\mathrm{p}-\mathrm{n}}=3.4 \times 10^{-3} \Omega$ when $\Delta T=30 \mathrm{~K}, T_{\mathrm{h}}=320 \mathrm{~K}$ and $T_{\mathrm{c}}=290 \mathrm{~K}$. For M-II with $h_{\mathrm{i}}=1.6, \quad R_{\mathrm{p}-\mathrm{n}}=5.98 \times 10^{-3} \Omega$ when $\Delta T=37 \mathrm{~K}$, $T_{\mathrm{h}}=327 \mathrm{~K}$ and $T_{\mathrm{c}}=290 \mathrm{~K}$. Increase of $h_{\mathrm{i}}$ leads to decrease of the total resistance in the p-n module. It is found that the $R_{\text {bonded-area }}$ is nearly the same for M-I and M-II samples: $R_{\text {bonded-area }}=1.17 \times 10^{-3} \Omega$ for $\mathrm{M}-\mathrm{I}$ and $R_{\text {bonded-area }}=$ $1.37 \times 10^{-3} \Omega$ for M-II. This implies that the geometrical size of $h_{\mathrm{i}} \times w$ has little direct influence on the resistance of bonded-area.

To understand why $R_{\text {bonded-area }}$ is nearly irrespective to the

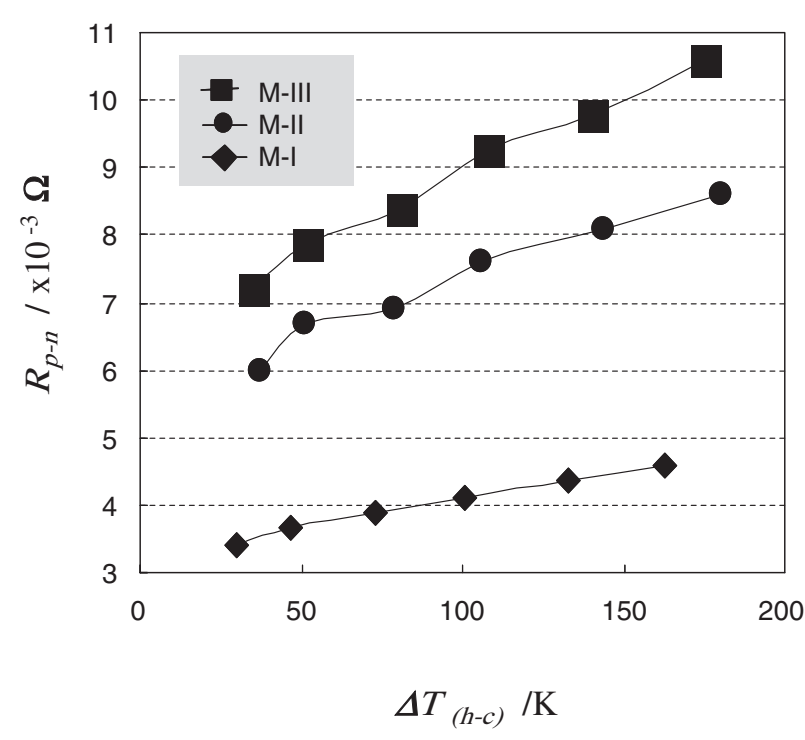

Fig. 6 Variation of total p-n resistance $\left(R_{\mathrm{p}-\mathrm{n}}\right)$ with temperature difference $\left(\Delta T_{(\mathrm{h}-\mathrm{c})}\right)$ for three types of module samples.

geometrical size, the electric current density analysis was performed with the loading conditions as shown in Table 2 and Fig. 3(b) in the case to maximize the output power. Figure 7 compares the current density distributions between two module samples. When the electric field is applied to the module, the carriers move in a series circuit of (p-leg area) $\rightarrow$ (bonded area) $\rightarrow$ (n-leg area). The highest electric current density is observed at the near top-corner region of wedge. To be noticed from Fig. 7(a), upper region of module has much lower electric current density. It is about 0.001 times smaller than other lower regions. This result suggests that the most part of bonded area with $h_{\mathrm{i}} \times w$ is not effective as a carrierpath. In this $\mathrm{p}-\mathrm{n}$ module configuration, carriers are driven by the applied electric field to turn over from p-leg to n-leg around the corner of wedge. The effective carrier-path area was denoted in Fig. 7 by $A_{1}$ and $A_{2}$ for M-I and M-II, respectively. Since $A_{1} \simeq A_{2}, M-I$ and $M-I I$ have nearly the same $R_{\text {bonded-area }}$.

\subsection{Evaluation on the p-n module open circuit voltage}

The open circuit voltage, $V_{\mathrm{oc}}$, is given by $\alpha_{\mathrm{p}-\mathrm{n}} \cdot \Delta T$ in the non-current state or when $I=0$. Here $\alpha_{\mathrm{p}-\mathrm{n}}$ is a total Seebeck coefficient of module. To measure $\alpha_{\mathrm{p}-\mathrm{n}}$ for this $V_{\mathrm{oc}}$, temperature difference is measured as accurately as possible. Three holes were drilled in the thermoelectric module to have three holes with the diameter of $0.5 \mathrm{~mm}$. As shown in Fig. 8, several thermocouples are fixed at the top of module, at the 
(a)

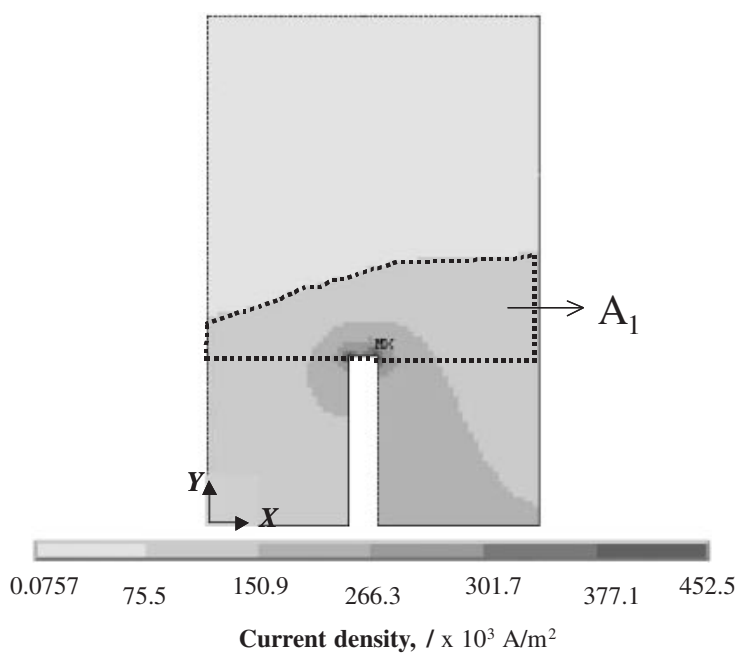

(b)

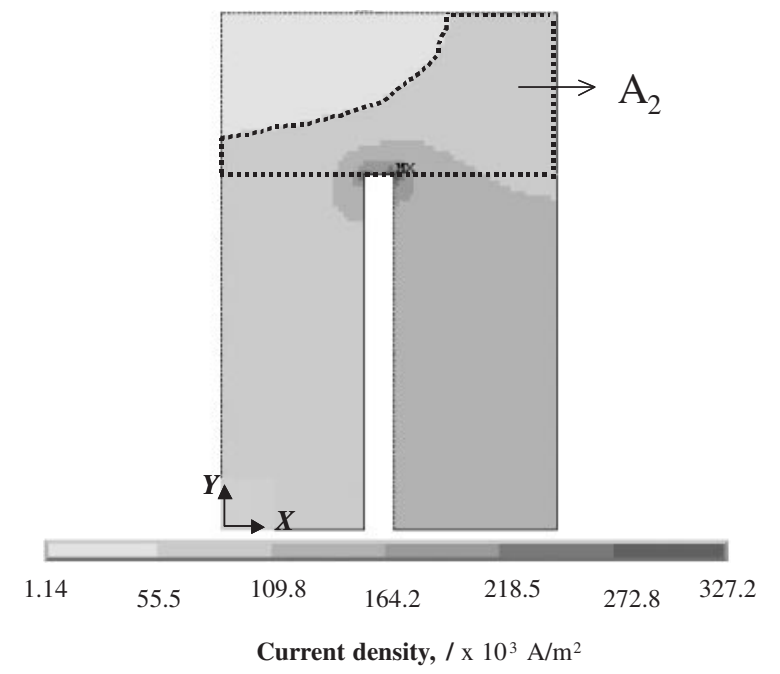

Fig. 7 Electric current density distribution at maximum output power calculated by computer-aided analysis: (a) M-I sample, and (b) M-II sample.

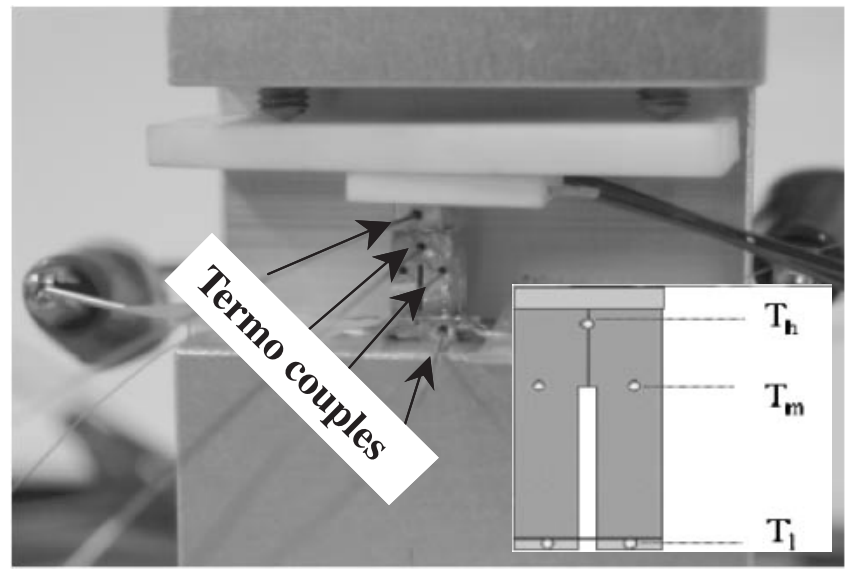

Fig. 8 Experimental set-up for measurement of module characteristics.

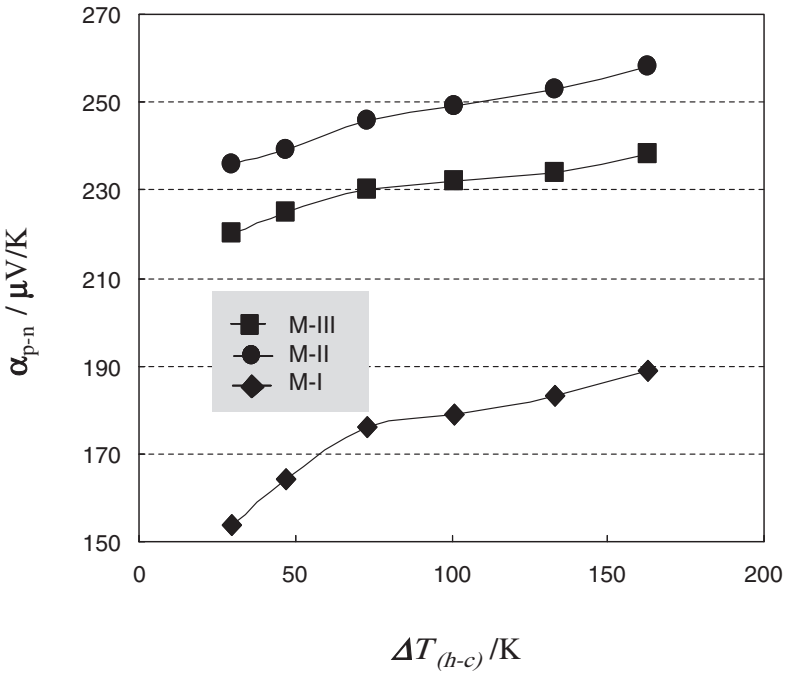

Fig. 9 Variation of total Seebeck coefficient $\left(\alpha_{\mathrm{p}-\mathrm{n}}\right)$ with temperature difference $\left(\Delta T_{(\mathrm{h}-\mathrm{c})}\right)$ for three types of module samples.

top of leg and at the copper electrode. Variation of total $\alpha_{\mathrm{p}-\mathrm{n}}$ $\left(=V_{\mathrm{oc}} / \Delta T_{(\mathrm{h}-\mathrm{c})}\right)$ with the applied temperature difference $\left(\Delta T_{(\mathrm{h}-\mathrm{c})}\right)$ for three types of module samples is shown in Fig. 9.

The Seebeck coefficient is given by $|\alpha|=\gamma-\ln (n)$, where $\gamma$ is the scattering parameter and $\mathrm{n}$ is the carrier concentration. The first term denotes the scattering contribution and the second term, $\ln (n)$, the carrier concentration contribution to Seebeck coefficient. The Seebeck coefficient increases in all modules with $\Delta T_{(\mathrm{h} \text {-c) }}$ because of carrier-phonon scattering and extrinsic behavior below $400 \mathrm{~K}$ in $\mathrm{Bi}-\mathrm{Te}$ system. Even for the same interface layer height $\left(h_{\mathrm{i}}\right), \alpha_{\mathrm{p}-\mathrm{n}}$ of M-II is larger than that of M-III. This fact implies that the carrier depletion zone plays a role to obstruct the generation of voltage difference.

Here $\alpha_{\mathrm{p}-\mathrm{n}}=153.5 \mu \mathrm{V} / \mathrm{K}$ for M-I when $\Delta T_{(\mathrm{h}-\mathrm{c})}=30 \mathrm{~K}$, $T_{\mathrm{h}}=320 \mathrm{~K}$ and $T_{\mathrm{c}}=290 \mathrm{~K}$, and, $\alpha_{\mathrm{p}-\mathrm{n}}=235.2 \mu \mathrm{V} / \mathrm{K}$ for $\mathrm{M}-$ II when $\Delta T_{(\mathrm{h}-\mathrm{c})}=37 \mathrm{~K}, T_{\mathrm{h}}=327 \mathrm{~K}$ and $T_{\mathrm{c}}=290 \mathrm{~K}$. Decrease of $h_{\mathrm{i}}$ leads to increase of the total Seebeck coefficient in the $\mathrm{p}$-n module.

To analyze this $\alpha_{\mathrm{p}-\mathrm{n}}$ theoretically, the temperature distribution is first calculated under the loading conditions as shown in Table 2 and Fig. 3(a). As shown in Fig. 10, the p-n module is subjected to thermal loading mainly in the $Y$ direction. The calculated temperature $T\left(h_{\mathrm{i}}\right)$ at $Y=h_{\mathrm{i}}$ is compared with the measured temperature $T_{\mathrm{m}}$ in Fig. 8. For M-I, $T\left(h_{\mathrm{i}}\right)=300.7 \mathrm{~K}$ and $T_{\mathrm{m}}=301.0 \mathrm{~K}$, while $T\left(h_{\mathrm{i}}\right)=$ $316.2 \mathrm{~K}$ and $T_{\mathrm{m}}=316 \mathrm{~K}$ for M-II. This fairly good agreement for two $\mathrm{p}-\mathrm{n}$ modules proves that temperature difference is accurately predicted by the present theoretical analysis. From the above calculated temperature distribution, the voltage distribution is directly estimated as a piecewise constant function in each element. The absolute voltage $|V|$ changes along the module height or in the $Y$-axis are calculated for M-I, II and shown in Fig. 11. $V_{\text {bonded-area }}$ is defined by the difference of absolute voltage between $\mathrm{p}$ - and n-types at $Y=h_{\mathrm{i}}$. For M-I in Fig. 11(b), $\left|V_{\text {bond,p }}\right|-$ $\left|V_{\text {bond, } \mathrm{n}}\right|=1.525 \mathrm{mV}$ while $\left|V_{\text {bond,p }}\right|-\left|V_{\text {bond,n }}\right|=0.853 \mathrm{mV}$ for M-II in Fig. 11(c). Then, the open circuit voltage, $V_{\mathrm{oc}}$, is 
(a)

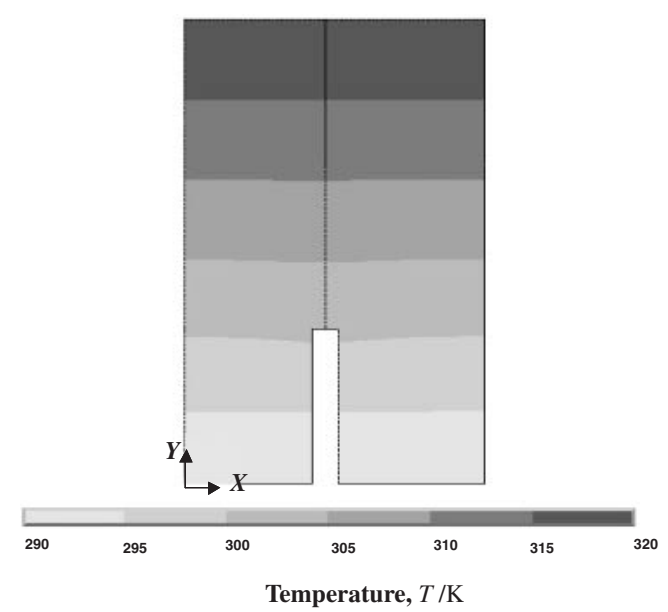

(b)

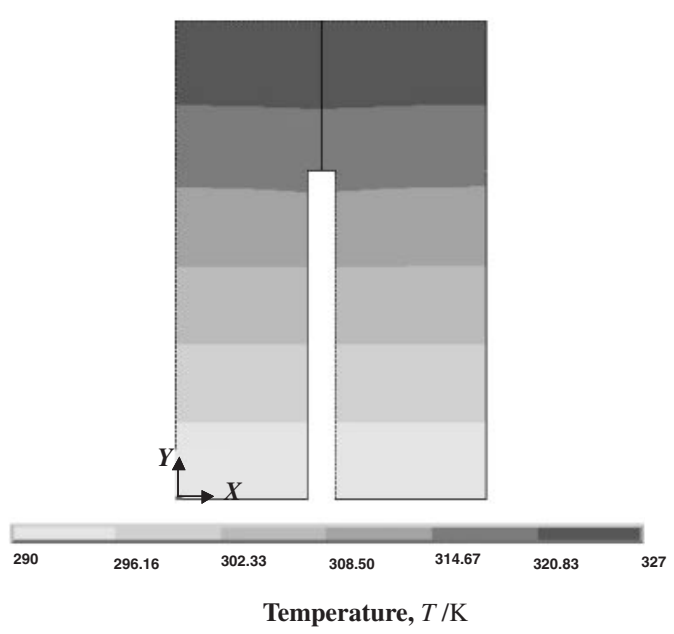

Fig. 10 Temperature distributions calculated by computer-aided analysis: (a) M-I sample, and (b) M-II sample.

written by

$$
\begin{aligned}
V_{\mathrm{oc}}= & V_{\mathrm{p}-\text { leg }}+V_{\mathrm{n}-\text { leg }}+\left|V_{\text {bond,p }}\right|-\left|V_{\text {bond } \mathrm{n}}\right|, \\
= & \left|\alpha_{\mathrm{p}-\operatorname{leg}}\right|\left(T_{\mathrm{m}}-T_{\mathrm{c}}\right)+\left|\alpha_{\mathrm{n}-\operatorname{leg}}\right|\left(T_{\mathrm{m}}-T_{\mathrm{c}}\right) \\
& +\alpha_{\text {bonded-area }}\left(T_{\mathrm{h}}-T_{\mathrm{m}}\right) .
\end{aligned}
$$

Here, $\alpha_{\mathrm{p}-\mathrm{leg}}=204 \mu \mathrm{V} / \mathrm{K}$ and $\alpha_{\mathrm{n}-\mathrm{leg}}=-125 \mu \mathrm{V} / \mathrm{K}$, respectively. The theoretical estimates of $V_{\mathrm{p}-\text { leg }}, V_{\mathrm{n} \text {-leg }}, V_{\text {bonded-area }}$, $V_{\mathrm{oc}}$ and $\alpha_{\mathrm{p}-\mathrm{n}}$ for two types of module samples are listed in Table 5. The experimentally measured $V_{\mathrm{oc}}$ is theoretically estimated by eq. (4) with the maximum error of $19.5 \%$ and $\alpha_{\mathrm{p}-\mathrm{n}}$ can be estimated with the maximum error of $9 \%$.

\subsection{Power generation characteristics of p-n modules}

In general, output power $\left(P_{\mathrm{g}}\right)$ and output voltage $\left(V_{\mathrm{g}}\right)$ of a thermoelectric module at constant $\Delta T$ are expressed as

$$
\begin{aligned}
& P_{\mathrm{g}}=V_{\mathrm{g}} \cdot I, \\
& V_{\mathrm{g}}=\left(\alpha_{\mathrm{p}-\mathrm{n}} \cdot \Delta T-R_{\mathrm{p}-\mathrm{n}} \cdot I\right) .
\end{aligned}
$$

For the load resistance, $R_{\mathrm{L}}$, the maximum output power (a)

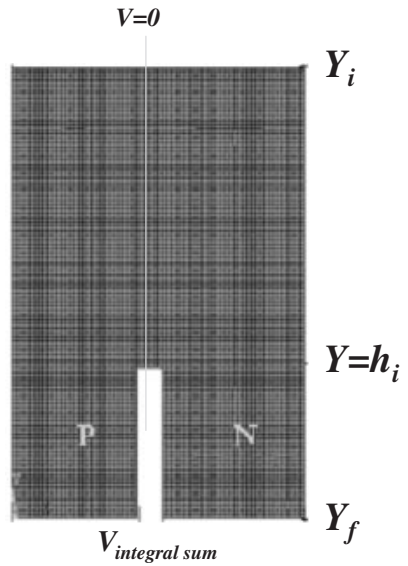

(b)

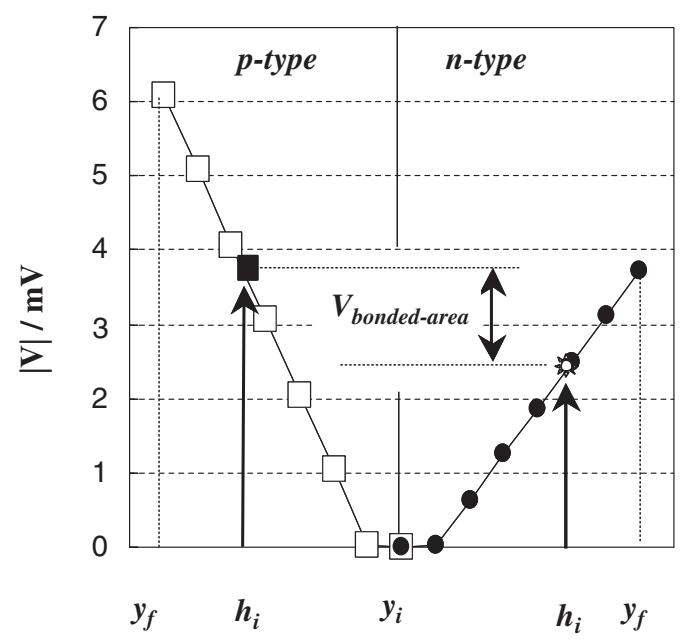

(c)

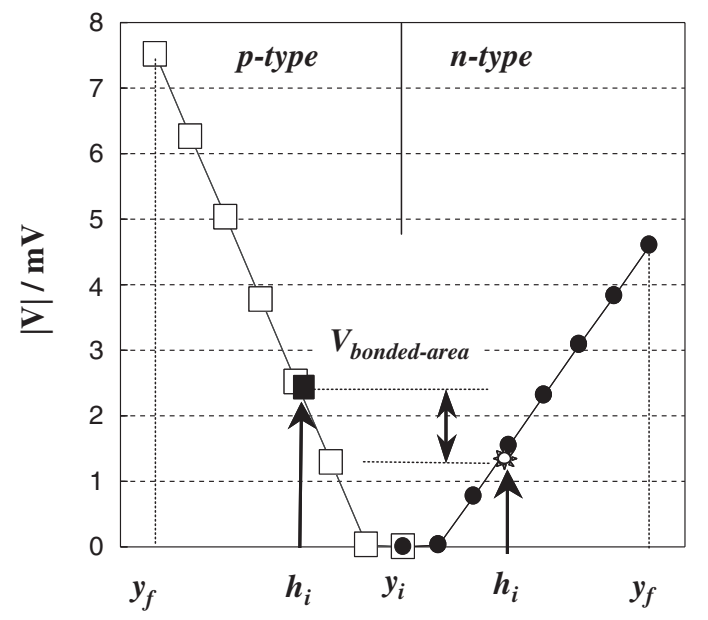

Fig. 11 Distributions of $|V|$ along the module height, $Y$ for p-n module samples: (a) p-n model with the coordinate $Y$ from $Y_{\mathrm{i}}$ to $Y_{\mathrm{f}}$, (b) $|V|$ for M-I sample, and (c) $|V|$ for M-II sample.

$\left(P_{\mathrm{g}, \max }\right)$ is generated when $R_{\mathrm{p}-\mathrm{n}}=R_{\mathrm{L}}$, as ${ }^{7)}$

$$
P_{\mathrm{g}, \max }=\frac{1}{4} \frac{\alpha_{\mathrm{p}-\mathrm{n}}^{2} \Delta T^{2}}{R_{\mathrm{p}-\mathrm{n}}} .
$$

Figure 12(a), (b) and (c) show the load characteristics or current dependence of $V_{\mathrm{g}}$ and $P_{\mathrm{g}}$ for temperature difference $(\Delta T)$ for samples M-I, M-II and M-III, respectively. In 
Table 5 Comparsion of thermoelectric data between experimental measurement and theoretical estimate for two types of module samples.

\begin{tabular}{|c|c|c|c|c|c|c|c|c|c|}
\hline \multirow{2}{*}{$\begin{array}{l}\text { Module } \\
\text { samples }\end{array}$} & \multicolumn{6}{|c|}{ Theoretical estimate } & \multicolumn{3}{|c|}{ Experimental result } \\
\hline & $\begin{array}{l}V_{\mathrm{p}-\mathrm{leg}} \\
(\mathrm{mV})\end{array}$ & $\begin{array}{l}V_{\text {n-leg }} \\
(\mathrm{mV})\end{array}$ & $\begin{array}{c}V_{\text {bonded-area }} \\
(\mathrm{mV})\end{array}$ & $\begin{array}{c}V_{\mathrm{oc}} \\
(\mathrm{mV})\end{array}$ & $\begin{array}{c}\Delta T_{(\mathrm{h}-\mathrm{c})} \\
(\mathrm{K})\end{array}$ & $\begin{array}{c}\alpha_{\mathrm{p}-\mathrm{n}} \\
(\mu \mathrm{V} / \mathrm{K})\end{array}$ & $\begin{array}{c}V_{\mathrm{oc}} \\
(\mathrm{mV})\end{array}$ & $\begin{array}{c}\Delta T_{(\mathrm{h}-\mathrm{c})} \\
(\mathrm{K})\end{array}$ & $\begin{array}{c}\alpha_{\mathrm{p}-\mathrm{n}} \\
(\mu \mathrm{V} / \mathrm{K})\end{array}$ \\
\hline M-I & 2.183 & 1.338 & 1.525 & 5.046 & 30 & 168.2 & 4.607 & 30 & 153.5 \\
\hline M-II & 5.345 & 3.275 & 0.853 & 9.473 & 37 & 256.0 & 8.702 & 37 & 235.2 \\
\hline
\end{tabular}

experiments, the output voltage and the output power were measured by applying the temperature difference between edges of the module. With increasing $\Delta T_{(\mathrm{h}-\mathrm{c})}\left(=T_{\mathrm{h}}-T_{\mathrm{c}}\right)$, both $V_{\mathrm{g}}$ and $P_{\mathrm{g}}$ increase, since $\alpha_{\mathrm{p}-\mathrm{n}}$ increase with $\Delta T_{\text {(h-c) }}$. For M-III module without metallic insert, the maximum output power $\left(P_{\mathrm{g}, \max }\right)$ is $42 \mathrm{~mW}$ at $\Delta T=175 \mathrm{~K}$. For M-I and M-II modules with metallic insert, $P_{\mathrm{g}, \max }$ reaches $52 \mathrm{~mW}$ at $\Delta T=163 \mathrm{~K}$ and $63.3 \mathrm{~mW}$ at $\Delta T=180 \mathrm{~K}$, respectively. This result suggests that the metallization at the p-n interface is effective to reduce $R_{\mathrm{p}-\mathrm{n}}$, and increase of output power.

Maximum output power is attained under the conditions with increasing $\alpha_{\mathrm{p}-\mathrm{n}}$ and $\Delta T$ or decreasing $R_{\mathrm{p}-\mathrm{n}}$. Increase of $\alpha_{\mathrm{p}-\mathrm{n}}$ or decrease of $R_{\mathrm{p}-\mathrm{n}}$ is limited by material design and processing. On the other hand, temperature difference can be increased as an external loading. In the conventional thermoelectric module, its operating temperature is limited by the presence of solder. Since the melting point of $\mathrm{Pb}$-free solder ranges 423 to $523 \mathrm{~K},{ }^{8)}$ the solder melts are ready to diffuse to p- and n-type materials even at the ambient temperature. In the present soldering-less process, the module is permitted to operate at relatively high temperature and large temperature difference can be applied in order to maximize the output power by eq. (8).

Even when using the present module unit at the vicinity of $T_{\mathrm{h}}=500 \mathrm{~K}$, no cracks are detected at all thermoelectric modules. No cracking takes place even when $\Delta T$ is controlled to increase or decrease within $\Delta T \leq 180 \mathrm{~K}$. This fact suggests that the SPS solid bonding technique can eliminate soldering process, especially when $\mathrm{Bi}-\mathrm{Te}$ base thermoelectric materials are used at relatively high temperature.

\section{Conclusions}

The thermoelectric p-n module in $\mathrm{Bi}-\mathrm{Te}$ system is successfully fabricated without soldering process by the SPS solid bonding technique. Both p-type $\left(\mathrm{Bi}_{0.4} \mathrm{Sb}_{1.6} \mathrm{Te}_{3}\right)$ and n-type $\left(\mathrm{Bi}_{2} \mathrm{Te}_{2.85} \mathrm{Se}_{0.15}\right)$ materials are prealloyed from elemental granule mixture of $\mathrm{Bi}, \mathrm{Sb}, \mathrm{Se}$ and $\mathrm{Te}$ and shearextruded to have preferable anisotropic texture. SPS solid bonding enables us to reduce the mutual atomic diffusion layer thickness across the p-n interface down to $2 \mu \mathrm{m}, 0.04$ times narrower than that for hot-pressed $p-n$ interface. The p-n interface resistance is further reduced by insitu metallization during SPS solid bonding processing. Thermoelectric p-n module characteristics is experimentally measured and theoretically evaluated through computer-aided analysis. Since both results are in good agreement, theoretically deduced expressions for modules are available to $\mathrm{p}-\mathrm{n}$ module design. Temperature for hot source can be increased up $500 \mathrm{~K}$ (a)

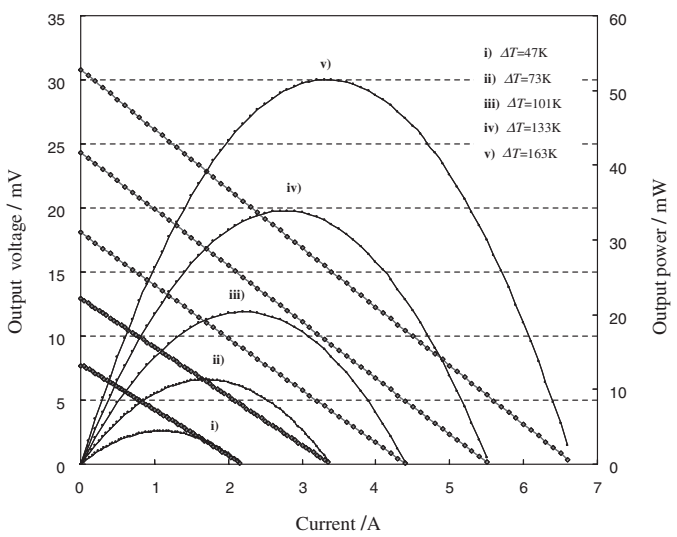

(b)

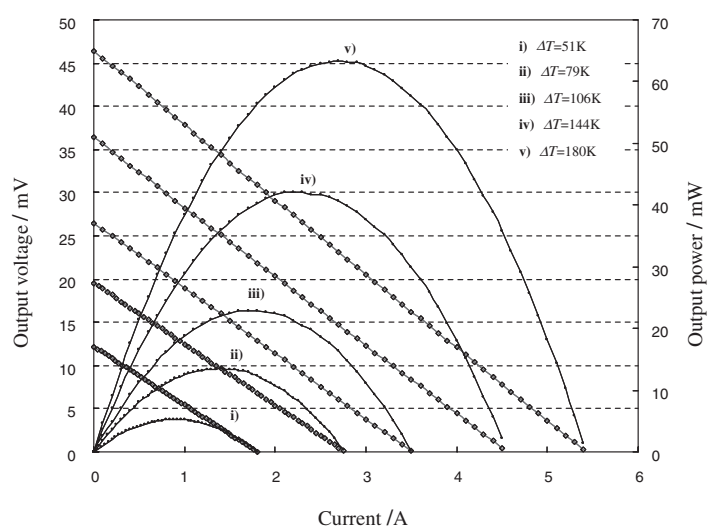

(c)

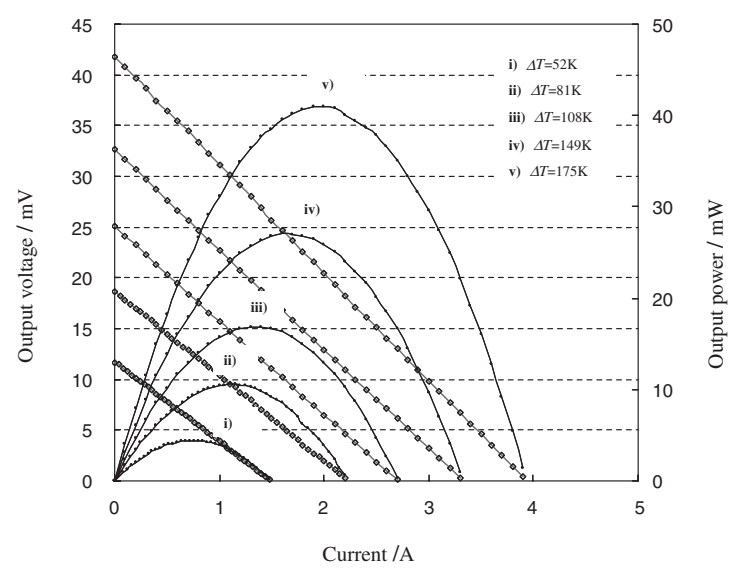

Fig. 12 Variation of output power and output voltage with temperature difference $(\Delta T)$ for three types of module samples: (a) $P_{\mathrm{g}}$ and $V_{\mathrm{g}}$ for M-I sample, (b) $P_{\mathrm{g}}$ and $V_{\mathrm{g}}$ for M-II sample, and (c) $P_{\mathrm{g}}$ and $V_{\mathrm{g}}$ for M-III sample. 
since no solders are used in the present model. Maximum output power is attained to be $63.3 \mathrm{~mW}$ at $\Delta T=180 \mathrm{~K}$ without any cracks in $\mathrm{p}-\mathrm{n}$ interface.

\section{REFERENCES}

1) D. M. Rowe: Renewable Energy 16 (1999) 1251-1256.

2) M. S. El-Genk, J. T. Seo and J. J. Buksa: J. Appl. Phys. 61 (1987) 20592064.
3) I. A. Nishida: Iron Steel 81 (1995) N454-N460.

4) S. S. Kim and T. Aizawa: Mater. Trans. 45 (2004) 918-924.

5) S. S. Kim, S. Yamamoto and T. Aizawa: J. Alloys Compds. 375 (2004) 107-113.

6) J. Y. Yang, T. Aizawa, A. Yamamoto and T. Ohta: Mater. Sci. Eng. B 85 (2001) 34-37.

7) D. J. Yeon, T. S. Oh and D. B. Hyun: J. Kor. Inst. Met. \& Mater. 38 (2000) 716-721.

8) M. Tanimoto, H. Tanaka, S. Suzuki and A. Matsuda: Furukawa Electric Review 19 (2000) 91-96. 